\title{
GAYA PEMIMPIN KEPALA RUANGAN DENGAN KEPUASAAN PERAWAT
}

\author{
Marlisa Rumondor \\ Lenny Gannika \\ Yolanda Bataha
}

\author{
Program Studi Ilmu KeperawatanFakultas kedokteran \\ Universitas Sam Ratualangi \\ E-mail:Lisarumondor@yahoo.com
}

\begin{abstract}
Job satisfaction is a pleasant or unpleasant emotional state where employees view work. Leadership style is a behavior pattern designed to integrate organizational goals with individual goals, to achieve a goal. Objective: To analyze the relationship between the leadership style of the room's head and the satisfaction of nurses at Bhayangkara Hospital. Samples: taken with a total sampling technique, which amounted to 49 people. Research design: analytic descriptive with cross sectional approach and sampling technique of 49 people Univariate analysis aims to explain and describe each researcher variable. In general, this analysis only describes the distribution and percentage of each variable that will be analyzed by univariate analysis. Bivariate analysis is an analysis carried out on two variables that are allegedly related or correlated, namely data analysis to see the independent variable (Head of the room leader style) and the dependent variable (Nurse satisfaction). The test used is the Chi-square test $\left(x^{\wedge} 2\right)$. Results: The Chisquare test obtained a value of $p=<0.05=$ 0.008. Conclusion: there is a significant relationship between the leadership style of the head of the room and the job satisfaction of nurses in Bhayangkara Manado Hospital.
\end{abstract}

Keywords: Leader Room Style, Nurse Satisfaction.

Abstrak: Kepuasan kerja merupakan keadaan emosional yang menyenangkan atau tidak menyenangkan dimana para karyawan memandang pekerjaan. Gaya kepemimpinan merupakan pola tingkah laku yang dirancang untuk mengintegrasikan tujuan organisasi dengan tujuan individu, untuk mencapai suatu tujuan. Tujuan: Menganalisis hubungan gaya pemimpinan kepala ruangan dengan kepuasan perawat di Rumah Sakit Bhayangkara. Sampel: diambil dengan teknik pengambilan total sampel, yaitu berjumlah 49 orang. Desain penelitian: deskriptif analitik dengan pendekatan cross sectional dan teknik pengambilan sampel 49 orang. Analisa Univariat bertujuan untuk menjelaskan dan mendeskripsikan setiap variabel peneliti. Pada umumnya dalam analisis ini hanya menjelaskan distribusi dan presentase dari setiap variabel. Variabel yang akan di analisa dengan anlisa univariat tingkat kepuasaan kerja perawat. Analisi Bivariat merupakan analisa yang dilakukan terhadap dua variabel yang diduga berhubungan atau berkolerasi yaitu analisa data untuk melihat variabel independen (Gaya pemimpin Kepala ruangan) dan variabel dependen (Kepuasan perawat). Uji yang digunakan adalah uji Chi-square $\left(x^{2}\right)$. Hasil penelitian: Uji Chisquare didapatkan nilai $\mathrm{p}=<0.05=0.008$. Kesimpulan: terdapat hubungan yang signifikan antara gaya kepemimpinan kepala ruang dengan kepuasan kerja perawat di di Rumah Sakit Bhayangkara Manado.

Kata Kunci: Gaya Pemimpin Kepala Ruangan, Kepuasan Perawat. 


\section{PENDAHULUAN}

Kepuasan kerja ialah keadaan emosional yang menyenangkan atau tidak menyenangkan dimana para karyawan memandang pekerjaannya. Kepuasan kerja mencerminkan perasaan seseorang terhadap pekerjaannya. Hal tersebut terlihat dari sikap positif karyawan terhadap pekerjaan dan segala sesuatu yang dihadapi di lingkungan kerjanya. Bagian manajemen harus selalu memonitor kepuasan kerja karyawannya karena hal ini mempengaruhi sikap absensi, perputaran tenaga kerja, kepuasan kerja dan masalahmasalah penting lainnya (Sunyoto, 2012).

Rumah Sakit Bhayangkara Pemerintah Provinsi Sulawesi Utara memiliki jumlah tenaga perawat sebanyak 97 tenaga orang, dengan fasilitas dan jumlah ruang rawat ialah, ICU, IGD, OK, ruang Anak, ruang Kebidanan, ruang Interna/Bedah, Eldelweis, dan VIP dengan djumlah tenaga perawat ICU 10 orang, IGD 15 orang, OK 11 orang, ruang Anak 11 orang, ruang Kebidanan 15 orang, ruang Interna/Bedah 14 orang, Eldelweis 15 orang, dan VIP 13 orang.Rumah sakit juga memiliki tenaga dengan jenjang karir yang berbeda-beda yaitu Amd.Kep 49 orang, S.Kep 31 Orang, Ners 17 orang, Amd.Far 3 orang, Amd.Ak 4 orang, Amd.Keb 9 orang,Amd.Keu 1 orang, Amd.Rad 1 orang, Amd.Gizi 3 orang, Amd AB 1 orang, Amd.FT 2 orang, Amkg 2 orang. Dari hasil survai 8 perawat didapatkan 3 perawat merasa puas dengan gaya kepemimpinan kepala ruangan, 5 perawat mengatakan tidak puas dengan gaya kepemimpinan kepala ruangan alasan dari mereka gaya kepemimpinan kepala ruangan peneliti tanpa memberikan solusi yang jelas. Tertarik mengangkat judul "Hubungan Gaya Pemimpin Kepala Ruangan Dengan Kepuasaan Perawat Di Rumah Sakit Bhayangkara Manado".

\section{METODE PENELITIAN}

Alat pengumpulan data dalam peneliti ini merupakan Kusioner Gaya Pemimpin Kepala Ruangan Berjumlah 18 pertanyaan. Kuisioner ini telah digunakan pada penelitian dengan judul Pengaruh Gaya Kepemimpinan Kepala Ruangan Terhadap Semangat Kerja Perawat Pelaksana di Ruang Inap Rumah Sakit Umun Pusat Haji Adam Malik Medan, dengan pilihan jawaban $\mathrm{A}, \mathrm{B}, \mathrm{C}$, dan $\mathrm{D}$ (Friska, 2009).

Untuk skor nilai median, yaitu: Skor terendah x jumlah pertanyaan: 1 x 18 $=18$ Skor tertinggi $\mathrm{x}$ jumlah pertanyaan: 4 x $18=72$ Nilai median yang diperoleh: $(18+72)=90: 2+1=46$ Nilai median " 46 " selanjutnya sebagai cut off point (Sunyoto dan Setiawan, 2013) Baik jika $>46$ dan Kurang jika $\leq 46$ Kriteria Inklusi Perawat yang bersedia menjadi responden Perawat yang berada ditempat saat penelitian Kriteria Eksklusi Perawat yang sementara cuti disaat penelitian Perawat yang melaksanakan perjalanan dinas Perawat yang tidak bersedia dilakukan penelitian.

Analisa Univariat bertujuan untuk menjelaskan dan mendeskripsikan setiap variabel peneliti. Pada umumnya dalam analisia ini hanya menjelaskan distribusi dan presentase dari setiap variabel (Notoatmodjo, 2012). Variabel variabel yang akan di analisa dengan anlisa univariat Tingkat kepuasaan kerja perawat. Analisi Bivariat. Analisa Bivariat merupakan analisa yang dilakukan terhadap dua variabel yang diduga berhubungan atau berkolerasi (Notoatmodjo, 2012). Yaitu analisis data untuk melihat variabel independen (Gaya pemimpin Kepala ruangan) dan variabel dependen (Kepuasan perawat). Uji yang digunakan adalah uji Chi- square $\left(x^{2}\right)$ dengan tingkat kemaknaan $95 \%(\alpha=0,05)$. Pengumpulan data dilakukan sesuai jadwal yang diatur setelah mendapat persetujuan dari pembimbing dan penguji proposal, maka penelitian akan dilaksanakan di Rumah Sakit Bhayangkara. 
HASIL dan PEMBAHASAN

Tabel 1. Distribusi berdasarkan Umur responden di RS Bhayangkara, 2019

\begin{tabular}{lll}
\hline Umur Responden & $\mathbf{n}$ & $\mathbf{\%}$ \\
\hline$>25$ Tahun & 33 & 67.3 \\
$<25$ Tahun & 16 & 32.7 \\
\hline Total & $\mathbf{4 9}$ & $\mathbf{1 0 0 . 0}$ \\
\hline
\end{tabular}

Sumber data primer 2019

Berdasarkan tabel 1 diketahui bahwa sebagian besar umur responden berada pada umur $>25$ tahun yakni sebanyak 33 responden (67.3\%), dan pada kelompok umur $<25$ tahun sebanyak 16 responden (32.7\%). Berdasarkan hasil sebagian besar umur responden berada pada umur $>25$ tahun yakni sebanyak 33 responden (67.3\%) di Rumah Sakit Bhayangkara. Umur maksimal bisa bekerja sebagai PNS adalah 59 tahun, sehingga rata-rata umur pegawainya dibawah 59 tahun. Hasil penelitian ini menunjukan bahwa umur responden mayoritas masih muda dan usia produktif. Individu di usia produktif mampu mengoptimalkan kemampuan yang dimiliki untuk menghasilkan suatu hasil pekerjaan atau kegiatan. Individu akan menunjukan jati dirinya untuk mendapatkan pengakuan di lingkungan kerjanya bahwa usia muda juga mempunyai kemampuan berkarya, sebab diusia produktif individu tidak mudah puas dengan apa yang telah diperoleh melalui pekerjaanya. Salah satu faktor yang mempengaruhi kepuasan kerja adalah umur. Karyawan tua cenderung mencari aman dan mudahnya di dalam menjalankan tugas, demikian juga dengan tingkat kepuasan biasanya seseorang akan merasa puas dengan apa yang sudah didapat saat itu ( Hasibuan, 2014).

Tabel 2. Distribusi berdasarkan jenis kelamin responden di RS Bhayangkara.

\begin{tabular}{lll}
\hline Jenis Kelamin & $\mathbf{n}$ & $\mathbf{\%}$ \\
\hline Laki-Laki & 16 & 32.7 \\
Prempuan & 33 & 67.3 \\
\hline Total & $\mathbf{4 9}$ & $\mathbf{1 0 0 . 0}$
\end{tabular}

Sumber data primer 2019
Berdasarkan tabel 2 diketahui bahwa sebanyak 33 responden $(67.3 \%)$ yang berjenis kelamin perempuan, dan 16 responden $(32.7 \%)$ yang berjenis kelamin laki-laki. Berdasarkan hasil yang didapat bahwa sebanyak 33 responden (67.3\%) yang berjenis kelamin perempuan. Penelitian ini tidak sejalan dengan penelitian Mipratul, M. 2010, Hasil penelitian berjudul tingkat kepuasan kerja perawat di Instalasi rawat inap RSUD Pasaman Barat menunjukan bahwa kepuasan kerja responden laki-laki lebih tinggi sebesar $59,64 \%$ dibanding responden perempuan.

Tabel 3. Distribusi berdasarkan tingkat pendidikan responden di RS Bhayangkara, 2019

\begin{tabular}{ccc}
\hline $\begin{array}{c}\text { Tingkat } \\
\text { Pendidikan }\end{array}$ & n & \% \\
\hline DIII Keperawataan & 32 & 65.4 \\
S1 Ners & 17 & 34.6 \\
\hline Total & $\mathbf{4 9}$ & $\mathbf{1 0 0 . 0}$ \\
\hline
\end{tabular}

Sumber data primer 2019

Berdasarkan tabel 3 diketahui bahwa sebanyak 21 responden $(42.9 \%)$ pendidikan DIII Keperwatan, dan 11 responden $(22.4 \%)$ yang berpendidikan S1 Ners. Berdasarkan hasil yang didapat bahwa sebanyak 21 responden (42.9\%) pendidikan DIII Keperwatan. Hal ini menggambarkan bahwa kebutuhan di Rumah Sakit Bhayangkara dalam hal kepegawaian lebih banyak menggunakan tenaga perawat lulusan Diploma III Keperawatan, karena sesuai dengan kebijakan pimpinan untuk meningkatkan profesionalisme kerja pegawai dan sejalan dengan misi dari Rumah Sakit Bhayangkara yaitu meningkatkan profesionalisme sumber daya manusia. Semakin tinggi pendidikan akan semakin tinggi keinginan untuk memanfaatkan pengetahuan dan ketrampilan, juga akan memiliki kecenderungan untuk melakukan tuntutan, juga harapan yang lebih tinggi (Nawawi, 2011). Orang dengan pendidikan rendah jarang memikirkan sesuatu diluar 
daya nalarnya, sedangkan orang dengan pendidikan lebih tinggi cenderung memenuhi kebutuhannya sesuai dengan daya nalarnya yang tinggi akibat pengaruh tingkat pendidikannya yang tinggi. Sehingga orang dengan tingkat pendidikan lebih tinggi maka kepuasan kerjanya akan lebih rendah dari orang dengan pendidikan lebih rendah (Barata, 2006).

Tabel 4. Distribusi berdasarkan lama bekerja responden di RS Bhayangkara, 2019.

\begin{tabular}{lll}
\hline Lama Bekerja & $\mathbf{n}$ & $\mathbf{\%}$ \\
\hline$>3$ Tahun & 24 & 49.0 \\
$<3$ Tahun & 25 & 51.0 \\
\hline Total & $\mathbf{4 9}$ & $\mathbf{1 0 0 . 0}$
\end{tabular}

\begin{tabular}{lcc}
\hline Total & 49 & $\mathbf{1 0 0 . 0}$ \\
\hline Sumber data primer 2019 &
\end{tabular}

Berdasarkan pada Tabel 4 diketahui bahwa sebagian besar responden kurang dari 3 tahun responden $49 \%$ dan lebih dari 3 tahun responden $51,0 \%$. Rumah Sakit Bhayangkara dalam beberapa tahun ini mengalami perkembangan yang lumayan pesat, hal ini dibuktikan dengan bertambahnya ruang rawat inap. Bertambahnya ruang rawat inap tersebut berarti membutuhkan banyak perawat baru. Rumah Sakit Bhayangkara telah beberapa kali mengadakan tes seleksi penerimaan pegawai baru untuk ditempatkan di ruang rawat inap tersebut, sehingga kebanyakan perawat memiliki masa kerja dibawah masih $<3$ tahun. Masa kerja erat hubungannya dengan pengalaman, kepercayaan diri yang tinggi, pemahaman job description yang lebih baik.Sikap tersebut sangat diperlukan untuk menjadi pemimpin yang baik, yang bisa memotivasi, membimbing, mengarahkan pegawainya. Karyawan dengan masa kerja yang sudah lama, disamping mempunyai pengalaman, kepercayaan diri yang tinggi, pemahaman job descrpsion lebih baik, mereka juga menerima imbalan yang sesuai dengan harapan mereka. Ini akan meningkatkan kepuasan kerja karyawan dengan masa kerja lebih banyak.
Tabel 5. Distribusi berdasarkan Gaya Kepemimpinan responden di RS Bhayangkara, 2019

\begin{tabular}{lll}
\hline Gaya Pemimpin & n & \% \\
\hline Pemimpin bebas tindak & 17 & 34,7 \\
Pemimpin otoriter & 15 & 30,6 \\
Pemimpin partisipatif & 14 & 28,6 \\
Pemimpin demokratis & 3 & 6,1 \\
\hline Total & $\mathbf{4 9}$ & $\mathbf{1 0 0 . 0}$ \\
\hline Sumber data primer 2019 & &
\end{tabular}

Berdasarkan tabel 5 diketahui bahwa sebagian besar pemimpin bebas tindak sebanyak 17 responden $(34,7)$. Pemimpin otoriter sebanyak 15 responden $30,6 \%$. Selanjutnya pemimpin partisipatif sebanyak 14 responden $28,6 \%$ dan pemimpin demokratis sebanyak 3 responden $6,1 \%$. Penelitian ini sejalan dengan Arif, 2015 hubungan gaya kepemimpinan demo kratis kepala ruang dengan kepuasan kerja perawa $t$ di rumah Sakit Jiwa Daerah Dr. R.M. Soedjarwadi yang memperoleh data bahwa mayoritas gaya kepemimpinannya adalah sedang yaitu 24 orang $(63,2 \%)$. Pemimpin yang baik adalah pemimpin yang memperhatikan kesejahteraan karyawan atau petugas. Jadi dalam hal ini perawat merah puas dengan kepemimpinan yang demokratis kepada perawat. Perawat yang tidak puas karna ada kepala ruangan yang memberikan tanggung jawab tapi tidak memperhatikan beban kerja yang di imbangi oleh perawat.

Gaya ke-pemimpinan merupakan kepemimpinan yang menghargai sifat dan kemampuan staf, menggunakan kekuasaan posisi untuk mendorong ide dari staf, memberikan informasi seluas-luasnya dan pelimpahan sebagian wewenang kepada bawahan, keputusan dibuat secara musyawarah, prakarsa dapat datang dari bawahan, pengawasan tidak ketat. Namun ada beberapa yang belum dilakukan oleh kepala ruang diantaranya belum meratanya kesempatan untuk mendapatkan pelatihan, kritik yang lebih banyak diberikan daripada pujian, ketidak bebasan memilih 
kelompok bekerja yang merupakan bukti yang nampak pada gaya kepemimpinan di rumah Sakit Bhayangkara, sehingga menyebabkan gaya kepemimpinan hanya pada kategori kurang baik.

Tabel 6. Distribusi berdasarkan Kepuasan Perawat responden di RS Bhayangkara, 2019

\begin{tabular}{lll}
\hline $\begin{array}{l}\text { Kepuasaan } \\
\text { Perawat }\end{array}$ & n & \% \\
\hline Kurang Puas & 18 & 36,7 \\
Puas & 31 & 63,3 \\
\hline Total & $\mathbf{4 9}$ & $\mathbf{1 0 0 . 0}$ \\
\hline
\end{tabular}

Sumber: data primer 2019

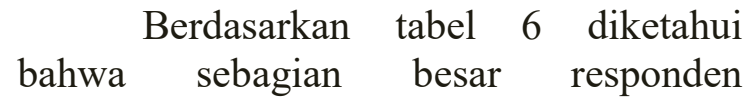
mempunyai kategori kepuasan kerja kurang puas yaitu sebanyak 32 responden $(65.3 \%)$. Hasil yang didapat bahwa sebagian besar responden mempunyai kategori kepuasan kerja kurang puas yaitu sebanyak 32 responden (65.3\%) dengan gaya kepemimpinan kepala ruangan karena memberikan beban kerja yang melebihi pada saat shift. Penelitian sejalan Wijanarko, 2015 tentang karakteristik individu dengan kepuasan kerja pada perawat RSJD Dr. Amino Gondohutomo Semarang dimana mendapatkan hasil kepuasan sebagian besar kurang puas 37.3 $\%$.

Penelitian Herman, 2013, tentang hubungan supervisi kepala ruangan dengan kepuasan perawat pelaksana di RSUD Liunkendage Tahuna Analisis bivariat supervisi kepala ruangan dengan kepuasan perawat pelaksana di RSUD Liunkendage Tahuna dari 69 responden, menunjukkan dominan pada supervisi kepala ruangan baik kepuasan perawat pelaksana puas. Hasil uji hipotesis dengan menggunakan uji chi-square $\left(x^{2}\right)$ pada kemaknaan 95\% $(\alpha$ $0,05)$ bantuan SPSS 20, diperoleh nilai $p=0,001$.

\section{Analisa Bivariat}

Tabel 7.Hubungan gaya pimpinan kepala ruangan dengan kepuasan perawat di Rumah Sakit Bhayangkara.

\begin{tabular}{|c|c|c|c|c|c|c|c|}
\hline \multirow{3}{*}{$\begin{array}{l}\text { Gaya } \\
\text { Kepemimpinan }\end{array}$} & \multicolumn{6}{|c|}{ Kepuasan Perawat } & \\
\hline & \multicolumn{2}{|c|}{$\begin{array}{l}\text { Kurang } \\
\text { Puas }\end{array}$} & \multicolumn{2}{|c|}{ Puas } & \multicolumn{2}{|c|}{ Total } & lue \\
\hline & $\mathbf{N}$ & $\%$ & $\mathbf{N}$ & $\%$ & $\mathbf{n}$ & $\%$ & \\
\hline Bebas Tindak & 2 & 11,8 & 15 & 88,2 & 17 & 100 & \\
\hline Otoriter & 6 & 40,0 & 9 & 60,0 & 15 & 100 & \\
\hline Partisipatif & 9 & 64,3 & 5 & 35,7 & 14 & 100 & 0,027 \\
\hline Demokratif & 1 & 33,3 & 2 & 66,7 & 3 & 100 & \\
\hline Total & 18 & 36,7 & 31 & 63,3 & 49 & 100 & \\
\hline
\end{tabular}

Sumber: data primer 2019

Berdasarkan tabel 7 didapatkan bahwa nilai signifikasi (p) value yaitu 0,027 yang berarti bahwa $\mathrm{p}<0,05$ sehingga Ha diterima dan Ho ditolak yang berarti ada korelasi atau hubungan yang signifikan antara gaya kepemimpinan kepala ruang dengan kepuasan kerja perawat di di Rumah Sakit Bhayangkara. Hubungan gaya kepemimpinan kepala ruangan dengan kepuasan perawat di Rumah Sakit Bhayangkara Manado. Berdasarkan hasil yang didapatkan bahwa nilai signifikasi (p) value yaitu 0,008 yang berarti bahwa $\mathrm{p}<0,05$ sehingga $\mathrm{Ha}$ diterima dan Ho ditolak yang berarti ada korelasi atau hubungan yang signifikan antara gaya kepemimpinan kepala ruang dengan kepuasan kerja perawat di di Rumah Sakit Bhayangkara.

Menurut Arif, 2015 bahwa kepuasan kerja berhubungan erat dengan kerja sama antara anak buah dengan pimpinan, semakin baik kerja sama yang dilakukan oleh pimpinan maka akan semakin baik kepuasan kerja anak buahnya. Hal ini juga didukung oleh Hasibuan dalam Arif, 2015 yang menyatakan bahwa salah satu faktor yang mempengaruhi kepuasan kerja adalah sikap pemimpin dalam kepemimpinannya, 
artinya bahwa sikap dari pemimpin yang ramah, mengerti akan pegawainya, adil akan dapat meningkatkan kepuasan kerja pegawainya (Malahayu Hasibuan, 2014).

Penelitian lain yang mendukung penelitian ini adalah penelitian yang berjudul hubungan gaya kepemimpinan dengan kepuasan kerja, menyimpulkan bahwa ada hubungan positif yang bermakna antara gaya kepemimpinan dengan kepuasan kerja (Yudi Nurhidayanto, 2009). Senada dengan penelitian ini, penelitian dengan judul pengaruh gaya kepemimpinan terhadap kepuasan kerja membuktikan bahwa ada pengaruh positif dan signifikan antara gaya kepemimpinan terhadap kepuasan kerja (Lina Nur Hidayati, 2006).

\section{SIMPULAN}

Hasil penelitian menunjukan ada hubungan antara gaya pemimpin kepala ruangan dengan kepuasan perawat di Rumah Sakit Bhayangkara Manado.

\section{DAFTAR PUSTAKA}

Arif Setiawan, 2015. Hubungan gaya kepemimpinan demokratis Kepala ruangdengan kepuasan kerja Perawat di rumah sakit jiwa daerah Dr. Rm. Soedjarwadi, Jurnal

Barata A.A. 2006. Dasar-dasar pelayanan prima, Jakarta: PT.Elex medika komputindo.

Friska. 2006. Hubungan Tingkat Kepuasan Perawat.

Herman. 2013. Tentang hubungan supervisi kepala ruangan dengan kepuasan perawat pelaksana di Rsud Liunkendage Tahuna, https://ejournal.unsrat.ac.id/inde x.php/eners/article/view/1763, diakses tanggal 1 februari 2019, jam 17.00 Wita.

Hasibuan. 2014. Manajemen Sumber Daya Manusia. Jakarta: Bumi Aksara.
Lina Nur Hidayati, 2006. Pengaruh gaya pemimpin transformation terhadap kepuasaan kerja.

Mipratul M. 2010. Kepuasaan kerja tenaga keperawataan diruang rawat inap RSUD Pasaman barat.

Notoatmodjo. 2012. Metodologi penelitian kesehatan.Jakarta: RinekaCipta

Nawawi. 2011. Manajemen sumber daya manusia; untuk bisnis yang kompetitif. Yogyakarta: UGM

PSIK Universitas Sam Ratulangi. 2011. Panduan Penulisan Tugas Akhir Proposal \& Skripsi

Sunyoto. 2012. Manajemen sumber daya manusia. Jakarta: PT. BUKU SERU

Wijanarko. 2015. Komunikasi penyadaran kritis terhadap perawat.

Yudi Nurhidayanto, N. 2009. Skripsi:

Beberapa faktor yang

berhubungan dengan kepuasan

kerja perawat di RSUD

Ambarawa, Yogyakarta:

Program Studi Ilmu

Keperawatan UGM 